\title{
The prevalence of obstructive sleep apnea in patients hospitalized for COPD exacerbation
}

\author{
Pavel Turcani ${ }^{\mathrm{a}, \mathrm{b}}$, Jana Skrickova ${ }^{\mathrm{b}, \mathrm{c}}$, Tomas Pavlikc, Eva Janousovac, Marek Orban ${ }^{\mathrm{a}}$
}

\begin{abstract}
Background. The concurrence of obstructive sleep apnea (OSA) and chronic obstructive pulmonary disease (COPD) is generally identified as an overlap syndrome. Only limited evidence is available on the prevalence of OSA in patients with stable COPD, and essentially no data on the prevalence of OSA in patients hospitalized for COPD exacerbation. The aims of the study were to determine the ratio of concurrence of OSA in patients hospitalized for COPD exacerbation and to identify the confounders of OSA detected in COPD subjects.

Methods. 101 patients were hospitalized for COPD exacerbation at the Department of Respiratory Diseases in the course of four months. Seventy-nine consecutive patients were enrolled in the study and in 35 of these subjects polygraphy was performed. Descriptive statistics, Mann-Whitney test, Kruskal-Wallis test, Spearman correlation and Fisher's test were used to summarize and evaluate results.

Results. In 18 (51.4\%) subjects with polygraphy examination, the apnea-hypopnea index (AHI) $\geq 5$ indicated the presence of OSA. The AHI value, and thus the severity of the sleep disorder, correlated with the class of the Mallampati score, presence of snoring, apnea, coronary heart disease, diabetes mellitus in patient's history, height, body mass index, neck, waist and hip circumferences, and the value of the Epworth sleepiness scale.

Conclusion. Polygraphy performed in patients hospitalized for exacerbation of COPD indicated an increased prevalence of OSA compared to the general population and stable COPD patients.
\end{abstract}

Key words: obstructive sleep apnea, COPD, overlap syndrome

Received: July 22, 2013; Accepted with revision: January 9, 2014; Available online: February 25, 2014 http://dx.doi.org/10.5507/bp.2014.002

aInternational Clinical Research Center, St. Anne's University Hospital in Brno, Czech Republic

${ }^{b}$ Department of Respiratory Diseases and TB, University Hospital Brno

IInstitute of Biostatistics and Analyses, Faculty of Medicine, Masaryk University, Brno

Corresponding author: Pavel Turcani, e-mail:pturcani@fnbrno.cz

\section{INTRODUCTION}

COPD is a disease characterized by airflow obstruction which is not fully reversible. In the European Union, the number of patients with COPD is estimated at 4-6\% of the population while in the U.S. adult population it is more than $5 \%$ (ref. ${ }^{1,2}$ ). COPD aggravates health-related quality of life, morbidity and mortality ${ }^{3}$. One measure of clinical severity and prognosis of this disease is the number of clinical deteriorations - exacerbations - per year ${ }^{46}$.

OSA is characterized by periodic apneas and hypopneas during sleep that cause daytime sleepiness, affect the quality of life and lead to changes in the cardiopulmonary system ${ }^{7}$. OSA is found in about $5 \%-15 \%$ of the population. The severity of the disease is expressed by the apnea-hypopnea index (number of apneas and hypopneas per hour - AHI) or oxygen desaturation index (number of decreases in oxygen saturation of hemoglobin per hour ODI). According to the AHI values, OSA can be divided into mild OSA (AHI below 5 per hour), moderate OSA (AHI 5-15 per hour), and severe OSA (AHI over 15 per hour). The presence of OSA affects the quality of life ${ }^{8}$, morbidity ${ }^{9,10}$ and mortality ${ }^{11}$. Patients with serious OSA are eligible for noninvasive ventilation (NIV), which improves their health and reduces mortality ${ }^{12-14}$.
A simultaneous occurrence of COPD and OSA in a patient is called the overlap syndrome (OS) $\left(\right.$ ref..$\left.^{15}\right)$. The results of studies on the prevalence of OS vary considerably. While some studies indicate a prevalence of OS of up to $29 \%\left(\right.$ ref. $\left.{ }^{16}\right)$, other studies seem to deny the link between COPD and (mild) OSA (ref. ${ }^{17,18}$ ). This is probably caused by the fact that the definitions of each of these diseases have been evolving over time, the diagnostic algorithms have not always been consistent, both COPD and OSA have several stages of severity, and different prevalence studies have been using different methodologies $^{19}$. Therefore it is not easy to compare similar data retrospectively. Compared with patients who have either OSA or COPD, patients with the OS have poorer quality of life, increased morbidity and mortality ${ }^{20-26}$. Although obese COPD patients are at high risk of serious events (hospitalization) per year ${ }^{27,28}$, literary recommendations to examine patients with stable COPD at sleep laboratories are made only cursorily, if at all ${ }^{1}$. To the best of our knowledge, there are no published data aiming at the identification of OSA in patients hospitalized for COPD exacerbations. No recommendations are currently available as to which patients hospitalized for COPD exacerbation should be examined in the sleep laboratory. As OSA in patients with COPD significantly aggravates their 
clinical status and the severity of their exacerbations, we hypothesized that polygraphy, a simple screening test in patients hospitalized for COPD exacerbation, could lead to detection of clinically significant forms of OS where NIV would significantly improve their outcomes.

\section{Objective}

Primary endpoint: What is the prevalence of OSA in patients hospitalized for COPD exacerbation?

Secondary endpoints: To describe characteristic clinical confounders of OS in population with COPD exacerbations.

\section{METHODS}

\section{Population}

The study was conducted at the Brno University Hospital's Department of Respiratory Diseases and Tuberculosis during the period from February to May 2013. After discontinuation of oxygen therapy (i.e. physician in charge of the case decided that the nighttime oxygen therapy was dispensable for one night), we first evaluated the characteristics of consecutive patients hospitalized for COPD exacerbation in the light of the study inclusion criteria (the patient was diagnosed with exacerbation of COPD indicated for hospitalization when this was the diagnosis on admission, based on the clinical decision of the physician and patient requiring antibiotic treatment and/or oral or intravenous corticosteroids). Those patients who gave consent to the examination, co-operated well, were not treated with long-term home oxygen therapy, had no qualitative impairment of consciousness which would limit their co-operation, had no tracheostomy cannula, were not treated for cancer, their performance status made it possible to treat them in standard wards, were not rehospitalized after having been already examined, and did not die during hospitalization, were included it in the study and examined polygraphically. Diseases listed among comorbidities were the following: cardiovascular diseases, diabetes mellitus, depression and hypertension. Diseases outside this list were tagged as "other disease". These were identified from the patient files and documentation. The study was approved by the Institutional Review Board and all patients enrolled signed the consent form.

\section{Study design}

In our single-center, prospective study all the patients who met the inclusion criteria and signed the consent form were examined by the same somnologist, member of the Respiratory Department. The following parameters were recorded: gender, height, weight, BMI, neck, waist, and hip circumferences, Mallampati score (i.e. classification of larynx visibility to predict the ease of intubation, from 1, easiest, to 4, most difficult), history of snoring, history of apnea, and results of the Epworth sleepiness scale. All patients were subsequently examined polygraphically. In order to ensure the reproducibility of the results, the polygraphy was performed after the clinical status of the patient was considered stable and did not require oxygenotherapy. Therefore most of the subjects underwent polygraphy within 2 days before discharge from the hospital. If the polygraphic record could not be evaluated (artifacts in the recordings from individual sensors etc.), the examination was repeated on the following day. The relationship between the symptoms and treatment was not studied.

\section{Limited polygraphy}

Monitored individuals were examined in a standard hospital ward. Polygraphy was performed using the EasyScreen (Heinen \& Löwenstein, Bad Ems, Germany). The person examined during the night (22:00 - 6:00) was equipped with a pulse oximeter, nasal cannula, and thoracic and abdominal belts to measure the movements of the chest and the abdomen. We monitored the prevalence of all types of apnea (defined as complete cessation of nasal flow for at least 10 seconds) and hypopnea (defined as at least a $50 \%$ limitation of tidal volumes for $10 \mathrm{~s}$, associated with at least a 3\% decrease in $\mathrm{O}_{2}$ saturation. Records were first evaluated with an automatic algorithm software supplied with the device by the manufacturer. All results were subsequently checked and manually edited by the somnologist. The following parameters were recorded: AHI, ODI, mean saturation during the limited polygraphy and percentage of saturation below 90\% (T90) of the total examination time.

\section{Statistics}

Descriptive statistics were used to summarize the data: frequency tables, median, minimum, and maximum. Statistical significance of differences in continuous COPD characteristics between patient groups was assessed using the Mann-Whitney test or Kruskal-Wallis test. The relationship between categorical COPD and OSAS characteristics was evaluated using the Fisher exact test. Scatter plots and Spearman rank correlation coefficients were used to visualize and quantify the relationship between continuous variables. Standard level for statistical significance $\alpha=0.05$ was used. Statistically significant results in the tables are shown in red.

\section{RESULTS}

In the course of four months, 101 patients were hospitalized for COPD exacerbation at the Department of Respiratory Diseases and TB - of these, 22 repeatedly. Seventy-nine other consecutive patients were reviewed with regard to the inclusion criteria (Table 1) and 35 of them were examined polygraphically (descriptive summary of their characteristics, see Table 2 and Table 3 ).

\section{Limited polygraphy evaluation with regard \\ to the prevalence of sleep apnea}

Eighteen out of $35(51.4 \%)$ examined patients had $\mathrm{AHI} \geq 5$, thus meeting the criteria for the presence of sleep apnea. 
Assessment of patient characteristics with regard to AHI

AHI and categorical characteristics (Table 2). A statistically significant relationship was found between AHI and the Mallampati score $(P=0.039)$, snoring $(P=0.005)$, apnea reported by the patient $(0.016)$, coronary artery disease $(P=0.004)$, DM $(P=0.010)$. It is self evident that higher values of the Mallampati score, the occurrence of snoring, apnea, coronary artery disease or DM mean an increase in AHI and thus a more severe OSA.

AHI and continuos characteristics (Table 3). A statistically significant relationship was found between categorized $\mathrm{AHI}$ and weight $(P=0.004)$, BMI $(P=0.001)$, neck circumference $(P=0.003)$, waist circumference $(P=0.001)$, hip circumference $(P=0.001)$ and Epworth scale $(P=0.005$ ). It is self evident that with increasing height, BMI, neck, waist, and hip circumferences and a higher value of the Epworth scale, AHI increases and so does the severity of OSA.

\section{Assessment of patient characteristics with regard to the ODI}

ODI and categorical characteristics. A statistically significant relationship was found between categorized ODI and the Mallampati score $(P=0.002)$ and the presence of comorbidities $(P=0.035)$. It is evident that an ODI above $15 / \mathrm{h}$ is more frequent in patients who had a higher Mallampati score and in patients with comorbities.

ODI and continuous characteristics. A statistically significant was found between categorized ODI and weight $(P=0.007)$, BMI $(P=0.020)$, neck circumference
Table 1. Reasons for non-inclusion into the study.

\begin{tabular}{lr}
\hline All & 79 \\
\hline ICU only & 8 \\
Home oxygen therapy & 11 \\
OSA on treatment & 9 \\
Tracheostomy cannula & 3 \\
Patient refused examination & 8 \\
Other & 5 \\
\hline Examined with limited polygraphy & 35 \\
\hline
\end{tabular}

Other: peptic ulcer rupture, myocardial infarction, acute abdominal complication requiring surgery.

( $P=0.001)$, waist circumference $(P=0.008)$, and hip circumference $(P=0.024)$. Patients with ODI over $15 / \mathrm{h}$, compared with those with ODI under $15 / \mathrm{h}$, had a greater weight, BMI, neck circumference, waist circumference and hip circumference.

\section{Assessment of characteristics of patients with regard to the mean saturation at night}

Mean saturation at night and categorical characteristics. A statistically significant relationship was found between mean night saturation and comorbidities $(P=0.027)$ and HT $(P=0.028)$. Patients with comorbidity and patients with HT had lower mean saturation at night than patients without comorbidity and patients without HT.

Table 2. Summary of categorical characteristics with regard to AHI.

\begin{tabular}{|c|c|c|c|c|c|}
\hline & & \multicolumn{3}{|c|}{ AHI } & \multirow{2}{*}{$P$ value* } \\
\hline & & Below $5 / \mathrm{h}$ & $5-15 / \mathrm{h}$ & Above $15 / \mathrm{h}$ & \\
\hline \multirow[t]{2}{*}{ Sex } & Men & $9(42.9 \%)$ & $6(28.6 \%)$ & $6(28.6 \%)$ & \multirow[t]{2}{*}{0.738} \\
\hline & Women & $8(57.1 \%)$ & $3(21.4 \%)$ & $3(21.4 \%)$ & \\
\hline \multirow[t]{3}{*}{ Mallampati score } & 1 & $9(56.3 \%)$ & $6(37.5 \%)$ & $1 \quad(6.3 \%)$ & \multirow[t]{3}{*}{0.039} \\
\hline & 2 & $5(45.5 \%)$ & $3(27.3 \%)$ & $3(27.3 \%)$ & \\
\hline & 3 or 4 & $3(37.5 \%)$ & $0 \quad(0.0 \%)$ & $5(62.5 \%)$ & \\
\hline Snoring & & $7(36.8 \%)$ & $3(15.8 \%)$ & $9(47.4 \%)$ & 0.005 \\
\hline Apnoe reported by patient & & $1(14.3 \%)$ & $1(14.3 \%)$ & $5(71.4 \%)$ & 0.016 \\
\hline Comorbidity & & $13(41.9 \%)$ & $9(29.0 \%)$ & $9(29.0 \%)$ & 0.158 \\
\hline CHD & & $2(14.3 \%)$ & $6(42.9 \%)$ & $6(42.9 \%)$ & 0.004 \\
\hline $\mathrm{DM}$ & & $1(10.0 \%)$ & $4(40.0 \%)$ & $5(50.0 \%)$ & 0.010 \\
\hline HT & & $10(47.6 \%)$ & $4(19.0 \%)$ & $7(33.3 \%)$ & 0.371 \\
\hline Depression & & $4(80.0 \%)$ & $1(20.0 \%)$ & $0 \quad(0.0 \%)$ & 0.340 \\
\hline Other disease & & $4(40.0 \%)$ & $2(20.0 \%)$ & $4(40.0 \%)$ & 0.617 \\
\hline Comorbidities - number & 0 & $4(100.0 \%)$ & $0 \quad(0.0 \%)$ & $0 \quad(0.0 \%)$ & 0.174 \\
\hline \multirow[t]{3}{*}{ (CHD, DM, HT, Depression) } & 1 & $6(60.0 \%)$ & $3(30.0 \%)$ & $1(10.0 \%)$ & \\
\hline & 2 & $5(41.7 \%)$ & $4(33.3 \%)$ & $3(25.0 \%)$ & \\
\hline & 3 and more & $2(22.2 \%)$ & $2(22.2 \%)$ & $5(55.6 \%)$ & \\
\hline
\end{tabular}

\footnotetext{
* Fisher exact test

$\mathrm{CHD}=$ Coronary heart disease

$\mathrm{DM}=$ Diabetes mellitus

HT $=$ Hypertension
} 
Table 3. Summary of continuous characteristics with regard to AHI.

\begin{tabular}{|c|c|c|c|c|}
\hline & $\begin{array}{l}\text { Below } 5 / h \\
\quad(n=17)\end{array}$ & $\begin{array}{l}5-15 / h \\
(n=9)\end{array}$ & $\begin{array}{l}\text { Above } 15 / \mathrm{h} \\
\qquad(\mathrm{n}=9)\end{array}$ & \\
\hline Med (Min;Max) & $\begin{array}{c}\text { Med } \\
\text { (Min;Max) }\end{array}$ & $\begin{array}{c}\text { Med } \\
\text { (Min;Max) }\end{array}$ & $\begin{array}{c}\text { Med } \\
\text { (Min;Max) }\end{array}$ & $P$ value* \\
\hline $\begin{array}{l}\text { Age (years) } \\
66(40 ; 92)\end{array}$ & $\begin{array}{c}65 \\
(45 ; 79)\end{array}$ & $\begin{array}{c}64 \\
(40 ; 92)\end{array}$ & $\begin{array}{c}67 \\
(60 ; 74)\end{array}$ & 0.524 \\
\hline $\begin{array}{l}\text { Weight }(\mathrm{kg}) \\
86(40 ; 180)\end{array}$ & $\begin{array}{c}78 \\
(40 ; 118)\end{array}$ & $\begin{array}{c}84 \\
(60 ; 131)\end{array}$ & $\begin{array}{c}112 \\
(84 ; 180)\end{array}$ & 0.004 \\
\hline $\begin{array}{l}\text { Height }(\mathrm{cm}) \\
172(150 ; 185)\end{array}$ & $\begin{array}{c}168 \\
(150 ; 183)\end{array}$ & $\begin{array}{c}175 \\
(167 ; 183)\end{array}$ & $\begin{array}{c}173 \\
(153 ; 185)\end{array}$ & 0.130 \\
\hline $\begin{array}{l}\text { BMI } \\
30(18 ; 56)\end{array}$ & $\begin{array}{c}28 \\
(18 ; 44)\end{array}$ & $\begin{array}{c}27 \\
(19 ; 39)\end{array}$ & $\begin{array}{c}37 \\
(32 ; 56)\end{array}$ & 0.001 \\
\hline $\begin{array}{l}\text { Neck circumference }(\mathrm{cm}) \\
42(32 ; 53)\end{array}$ & $\begin{array}{c}41 \\
(32 ; 45)\end{array}$ & $\begin{array}{c}42 \\
(34 ; 50)\end{array}$ & $\begin{array}{c}48 \\
(39 ; 53)\end{array}$ & 0.003 \\
\hline $\begin{array}{l}\text { Waist circumference }(\mathrm{cm}) \\
114(70 ; 182)\end{array}$ & $\begin{array}{c}102 \\
(70 ; 143)\end{array}$ & $\begin{array}{c}110 \\
(83 ; 137)\end{array}$ & $\begin{array}{c}135 \\
(116 ; 182)\end{array}$ & 0.001 \\
\hline $\begin{array}{l}\text { Hip circumference }(\mathrm{cm}) \\
111(79 ; 145)\end{array}$ & $\begin{array}{c}107 \\
(79 ; 140)\end{array}$ & $\begin{array}{c}111 \\
(94 ; 133)\end{array}$ & $\begin{array}{c}133 \\
(120 ; 145)\end{array}$ & 0.001 \\
\hline $\begin{array}{l}\text { Waist-to-hip ratio } \\
0.98(0.77 ; \text { I.30) }\end{array}$ & $\begin{array}{c}0.98 \\
(0.87 ; 1.09)\end{array}$ & $\begin{array}{c}0.94 \\
(0.77 ; 1.10)\end{array}$ & $\begin{array}{c}1 . \mathrm{II} \\
(0.87 ; 1.30)\end{array}$ & 0.613 \\
\hline $\begin{array}{l}\text { Epworth scale } \\
4(0 ; 24)\end{array}$ & $\begin{array}{c}2 \\
(0 ; 9)\end{array}$ & $\begin{array}{c}2 \\
(0 ; 12)\end{array}$ & $\begin{array}{c}8 \\
(3 ; 24)\end{array}$ & 0.005 \\
\hline
\end{tabular}

* Kruskal-Wallis test

BMI $=$ Body Mass Index

Table 4. Summary of mean nocturnal satuation with regard to OSA.

\begin{tabular}{|c|c|c|c|c|c|c|c|c|}
\hline AHI & $\mathrm{N}$ & Median & Minimum & Maximum & $\begin{array}{c}\text { Below } \\
95 \% \\
\text { N (\%) }\end{array}$ & $\begin{array}{c}\text { Below } \\
90 \% \\
\text { N (\%) }\end{array}$ & $\begin{array}{c}\text { Below } \\
85 \% \\
\text { N (\%) }\end{array}$ & $\begin{array}{c}\text { Below } \\
80 \% \\
\text { N (\%) }\end{array}$ \\
\hline Below $5 / \mathrm{h}$ & 17 & 90 & 80 & 95 & $\begin{array}{c}16 \\
(94.1 \%)\end{array}$ & $\begin{array}{c}6 \\
(35.3 \%)\end{array}$ & $\begin{array}{c}1 \\
(5.9 \%)\end{array}$ & $\begin{array}{c}0 \\
(0.0 \%)\end{array}$ \\
\hline Above $5 / \mathrm{h}$ & 18 & 89 & 60 & 94 & $\begin{array}{c}18 \\
(100.0 \%)\end{array}$ & $\begin{array}{c}11 \\
(61.1 \%)\end{array}$ & $\begin{array}{c}4 \\
(22.2 \%)\end{array}$ & $\begin{array}{c}1 \\
(5.6 \%)\end{array}$ \\
\hline
\end{tabular}

Mean saturation at night and continuous characteristics. Relationship between mean night saturation and both age and height was not statistically significant. There was a statistically significant relationship between mean night saturation and weight $(P=0.012)$, BMI $(P=0.003)$, neck circumference $(P=0.002)$, waist circumference $(P=0.002)$, hip circumference $(P=0.046)$, waist-to-hip ratio $(P=0.042)$ and Epworth scale value $(P=0.026)$. The higher the weight, BMI, neck, waist and hip circumferences, waistto-hip ratio and the Epworth scale, the lower as the mean nocturnal saturation (Fig. 1).

\section{Summary of mean nocturnal saturation with regard to} the presence of OSA

The difference between mean night saturation in patients with AHI below and above $5 / \mathrm{h}$ was not statistically significant (Mann-Whitney test: $P=0.153$ ). Patients with AHI below $5 /$ h (i.e. without OSA) had a median mean night saturation $90 \%$ (range $80 \%$ - 95\%), compared with $89 \%$ (range $60 \%$ - 94\%) in patients with AHI higher than $5 / \mathrm{h}$. Even in the group of patients with AHI below $5 / \mathrm{h}$ there were patients with SAT below 90\% (Table 4). 

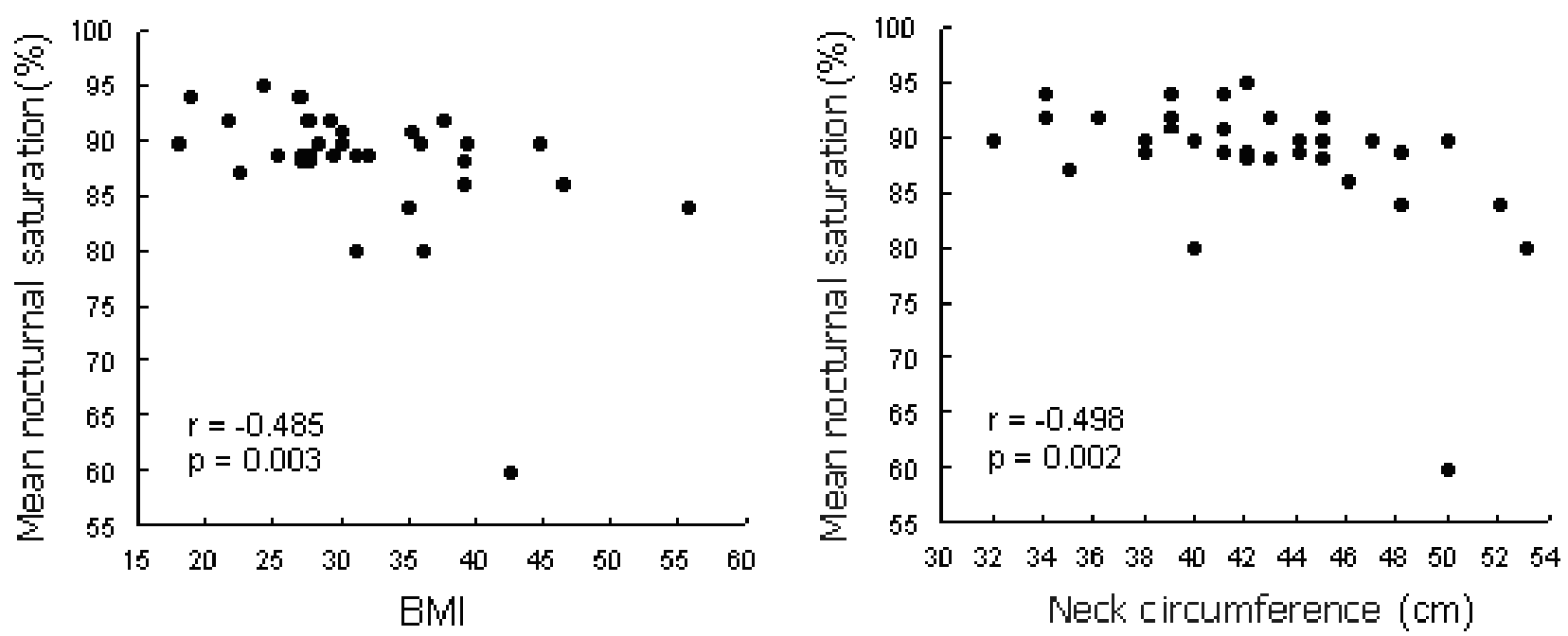

Fig. 1. Relationship between mean nocturnal saturation and BMI; relationship between mean nocturnal saturation and neck circumference.

\section{DISCUSSION}

Based on the results of the prospective data acquired in a COPD population with exacerbation requiring inhospital care, we found an increased prevalence of OSA (51\%). These patients meet the definition of OS, which is an important indicator of their prognosis. The AHI value, representing the severity of the sleep disorder, correlated with the following clinical and demographic confounders: the Mallampati score, presence of snoring and apnea in patient's history, presence of coronary heart disease and diabetes mellitus, height, BMI, neck, waist and hip circumferences, and the value of the Epworth sleepiness scale.

Studies that investigate OSA in patients with bronchial obstruction, or bronchial obstruction in patients with OSA (ref. ${ }^{16,29-31}$ ), are performed in patients with COPD in stable condition.

The presence of OSA in patients with COPD increases the risk of exacerbation and shortens the time to the first exacerbation ${ }^{26}$. It can be assumed that the examination focused on the search for OSA in patients hospitalized for COPD exacerbation will increase the probability of OS detection in comparison with the same examination done in patients with COPD without exacerbation. To date, this study is so far the only one that focuses on OSA in patients hospitalized for COPD exacerbation. The number of OS cases detected among consecutive patients hospitalized for COPD exacerbation probably has seasonal linkage as well as linkage with the character of the department where the research was carried out (greater prevalence of COPD exacerbations during the winter months, a greater number of patients hospitalized for COPD exacerbation at a specialist respiratory unit). Eighteen out 35 (51.4\%) patients met the criteria for the presence of sleep apnea. With regard to the number of these patients, it seems that once a patient is admitted to hospital for an exacerbation of COPD, the hospitalization could as well be used to perform polygraphy and identify
COPD patients with clinically severe forms of OS, where subsequent treatment with NIV might significantly improve their health and prognosis.

All the known correlations between patient characteristics and the presence of OSA (obesity, upper airway parameters, neck circumference, comorbidities such as hypertension and abnormalities of glucose metabolism) (ref. ${ }^{32-36}$ ), confirmed in our cohort of patients hospitalized for COPD exacerbation, could contribute to creation of a simple, clinically applicable scoring system enabling us to single out those among patients hospitalized for COPD exacerbation in whom polygraphic examination would make most sense. The COPD patient characteristics correlating with ODI are mostly identical with those correlating with AHI. This is in keeping with the use of ODI in the diagnosis of OSA in non-COPD population.

$27-70 \%$ patients with COPD experience a deterioration of saturation during sleep, compared to waking state at rest ${ }^{16,37,38}$. Nocturnal oxygen desaturation is a marker of increased mortality in COPD (ref. ${ }^{39}$ ). In all patients we examined, the value of nocturnal hypoxemia correlated with the presence of coronary heart disease, hypertension and obesity-related parameters (see above and Fig. 1). This was due to the proportion of OSA patients in the sample.

The difference between patients with AHI below and above $5 / \mathrm{h}$ in the mean nocturnal saturation was statistically insignificant (Mann-Whitney test: $P=0.153$ ). This means that in some patients without OS where daytime normoxemia might vindicate the termination of oxygen therapy, hypoxemia occurred during the night. It is not clear in which patients this nighttime hypoxemia persisted long enough to worsen their prognosis. Routine polygraphic examination of COPD patients hospitalized for exacerbation could potentially diagnose this high-risk group of patients with significant nocturnal hypoxemia.

There are several limitations of the study protocol which should be addressed. First, the patient population was small. Nevertheless, we are not aware of any published study referring to this specific topic and therefore 
this can be considered a pilot project. Second, the difference between the total number of subjects and those undergoing polygraphy (101 vs. 35) was due to the health conditions of the patients or their collaboration and not due to selection bias.

There are a number of interesting questions arising from the results. We have no data available on the criteria for assessment of OSA (including the severity) in patients hospitalized for COPD exacerbation. An interesting question would be to study possible pathophysiological crosstalk between OSA and COPD mechanisms by performing control polygraphy during the post-exacerbation recovery. In order to answer these and other questions, further prospective studies on larger populations with COPD are warranted.

\section{CONCLUSION}

Polygraphy performed in patients hospitalized for exacerbation of COPD indicated increased prevalence of OSA (including moderate and severe stages) compared to general population and stable COPD patients.

\section{ACKNOWLEDGEMENT}

Supported by European Regional Development Fund - Project FNUSA-ICRC (No. CZ.1.05/1.1.00/02.0123).

Author contributions: PT: literature search, manuscript writing and data collection; PT, MO: study design; TP, EJ: data analysis; PT, MO, JS: data interpretation; TP, EJ: statistical analysis, figures.

Conflict of interest statement: The authors stated that there are no conflicts of interest regarding the publication of this article.

\section{REFERENCES}

1. Qaseem A, Wilt TJ, Weinberger SE et Hanania NA, Criner G, van der Molen T, Marciniuk DD, Denberg T, Schünemann H, Wedzicha W MacDonald R, Shekelle P; American College of Physicians; American College of Chest Physicians; American Thoracic Society; European Respiratory Society. Diagnosis and management of slable chronic obstructive pulmonary disease: a clinical practice guideline uptdate for the ACP, ACCP, ATS and ERS. Ann Intern Med 2011;155:179-91.

2. Minino AM, Xu JQ, Kochanek K. Deaths: preliminary data for 2008 . Natl Vital Stat Rep 2010;59:7.

3. Pauwels RA, Rabe KF. Burden and clinical features of chronic obstructive pulmonary disease. Lancet 2004;365:613-20.

4. Donaldson GC, Seemungal TA, Bhowmik A, Wedzicha JA. Relationship between exacerbation frequency and lung function decline in chronic obstructive pulmonary disease. Thorax 2002;57(10):847-52. Erratum in: Thorax 2008;63(8):753.

5. Spencer S, Jones PW. Time course of recovery of health status following an infective exacerbation of chronic bronchitis. GLOBE Study Group.Thorax 2003;58(7):589-93.

6. Almagro P, Calbo E, Ochoa de Echagüen A, Barreiro B, Quintana S, Heredia JL, Garau J. Mortality after hospitalization for COPD. Chest 2002;121(5):1441-8.

7. Quan SF, Howard BV, Iber C, Kiley JP, Nieto FJ, O'Connor GT, Rapoport DM, Redline S, Robbins J, Samet JM, Wahl PW. The Sleep Heart Health Study: design, rationale, and methods. Sleep 1997;20(12):1077-85.
8. Akashiba T, Kawahara S, Akahoshi T, Omori C, Saito O, Majima T, et Horie T. Relationship between quality of life and mood or depression in patients with severe obstructive sleep apnea syndrome. Chest 2002;122(3):861-5.

9. Marin JM, Carrizo SJ, Vicente E, Agusti AG. Longterm cardiovascular outcomes in men with obstructive sleep apnoea-hypopnoea with or without treatment with continuous positive airway pressure: an observational study. Lancet 2005;365:1046-53.

10. Kendzerska T, Mollayeva T, Gershon AS, Leung RS, Hawker G, Tomlinson G. Untreated obstructive sleep apnea and the risk for serious long-term adverse outcomes: A systematic review. Sleep Med Rev 2014;18(1):49-59. doi: 10.1016/j.smrv.2013.01.003

11. Lavie P, Herer P, Peled R, Berger I, Yoffe N, Zomer J, Rubin AH. Mortality in sleep apnea patients: a multivariate analysis of risk factors. Sleep 1995;18(3):149-57.

12. Anandam A, Patil M, Akinnusi M, Jaoude P, El Solh AA. Cardiovascular Mortality in Obstructive Sleep Apnea Treated with Continuous Positive Airway Pressure or Oral Appliance: an Observational Study. Respirology 2013;18(8):1184-90. doi: 10.1111/resp.12140

13. Kaneko Y, Floras JS, Usui K, Plante J, Tkacova R, Kubo T, Ando S, Bradley TD. Cardiovascular effects of continuous positive airway pressure in patients with heart failure and obstructive sleep apnea. N Engl J Med 2003;348(13):1233-41.

14. Pepperell JC, Ramdassingh-Dow S, Crosthwaite N, Mullins R, Jenkinson C, Stradling JR, Davies RJ. Ambulatory blood pressure after therapeutic and subtherapeutic nasal continuous positive airway pressure for obstructive sleep apnoea: a randomised parallel trial. Lancet 2002;359:204-10.

15. Flenley DC. Sleep in chronic obstructive lung disease. Clin Chest Med 1985;6(4):651-61.

16. Lopez-Acevedo MN, Torres-Palacios A, Elena Ocasio-Tascon M, Campos-Santiago Z, Rodriguez-Cintron W. Overlap syndrome: an indication for sleep studies?: a pilot study. Sleep Breath 2009;13(4):40913.

17. Sanders $M H$, Newman $A B$, Haggerty $C L$, Redline $S$, Lebowitz $M$, Samet J, O'Connor GT, Punjabi NM, Shahar E; Sleep Heart Health Study. Sleep and sleep-disordered breathing in adults with predominantly mild obstructive airway disease. Am J Respir Crit Care Med 2003;167(1):7-14.

18. Bednarek M, Plywaczewski $R$, Jonczak $L$, Zielinski J. There is no relationship between chronic obstructive pulmonary disease and obstructive sleep apnea syndrome: a population study. Respiration 2005;72(2):142-9.

19. Owens RL, Malhotra A. Sleep-Disordered Breathing and COPD: The Overlap Syndrome. Respir Care 2010;55(10):1333-44.

20. Mermigkis C, Kopanakis A, Foldvary-Schaefer N, Golish J, Polychronopoulos V, Schiza S, Amfilochiou A, Siafakas N, Bouros D. Health-related quality of life in patients with obstructive sleep apnoea and chronic obstructive pulmonary disease (overlap syndrome). Int J Clin Pract 2007;61(2):207-11.

21. Bradley TD, Rutherford R, Grossman RF, Lue F, Zamel N, Moldofsky $\mathrm{H}$, Phillipson EA. Role of daytime hypoxemia in the pathogenesis of right heart failure in the obstructive sleep apnea syndrome. Am Rev Respir Dis 1985;131(6):835-9.

22. Bradley TD, Rutherford R, Lue F, Moldofsky H, Grossman RF, Zamel N, Phillipson EA. Role of diffuse airway obstruction in the hypercapnia of obstructive sleep apnea. Am Rev Respir Dis 1986;134(5):920-4.

23. Fletcher EC, Levin DC. Cardiopulmonary hemodynamics during sleep in subjects with chronic obstructive pulmonary disease. The effect of short- and long-term oxygen. Chest 1984;85(1):6-14.

24. Douglas NJ, White DP, Weil JV, Pickett CK, Zwillich CW. Hypercapnic ventilatory response in sleeping adults. Am Rev Respir Dis 1982;126(5):758-62.

25. Lavie $P$, Herer $P$, Lavie L. Mortality risk factors in sleep apnoea: a matched case-control study. J Sleep Res 2007;16(1):128-34.

26. Marin JM, Soriano JB, Carrizo SJ, Boldova A, Celli BR. Outcomes in patients with chronic obstructive pulmonary disease and obstructive sleep apnea: the overlap syndrome. Am J Respir Crit Care Med 2010;182(3):325-31.

27. Burgel PR, Paillasseur JL, Peene B, Dusser D, Roche N, Coolen J, Troosters T, Decramer M, Janssens W. Two distinct chronic obstructive pulmonary disease (COPD) phenotypes are associated with high risk of mortality. PLoS One 2012;7(12):e51048. doi: 10.1371/journal. pone.0051048

28. Garcia-Aymerich J, Gómez FP, Benet M, Farrero E, Basagaña X, Gayete 
À, Paré C, Freixa X, Ferrer J, Ferrer A, Roca J, Gáldiz JB, Sauleda J, Monsó E, Gea J, Barberà JA, Agustí À, Antó JM; PAC-COPD Study Group. Identification and prospective validation of clinically relevant chronic obstructive pulmonary disease (COPD) subtypes. Thorax 2011;66(5):430-7. doi: 10.1136/thx.2010.154484

29. Guilleminault C, Cummiskey J, Motta J. Chronic obstructive airflow disease and sleep studies. Am Rev Respir Dis 1980;122(3):397-406.

30. Fletcher EC, Schaaf JW, Miller J, Fletcher JG. Long-term cardiopulmo nary sequelae in patients with sleep apnea and chronic lung disease. Am Rev Respir Dis 1987;135(3):525-33.

31. Buist AS, McBurnie MA, Vollmer WM, Gillespie S, Burney P, Mannino DM, Menezes AM, Sullivan SD, Lee TA, Weiss KB, Jensen RL, Marks GB, Gulsvik A, Nizankowska-Mogilnicka E; BOLD Collaborative Research Group. International variation in the prevalence of COPD (the BOLD Study): a population-based prevalence study. Lancet 2007;370(9589):741-50.

32. Hoffstein V, Szalai JP. Predictive value of clinical features in diagnosing obstructive sleep apnea. Sleep 1993;16(2):118-22.

33. Schwab RJ, Gupta KB, Gefter WB, Metzger LJ, Hoffman EA, Pack AI. Upper airway and soft tissue anatomy in normal subjects and patients with sleep-disordered breathing. Significance of the lateral pharyngeal walls. Am J Respir Crit Care Med 1995;152(5 Pt 1):1673-
34. Leiter JC. Upper airway shape: Is it important in the pathogenesis of obstructive sleep apnea? Am J Respir Crit Care Med 1996;153(3):8948.

35. Malhotra A, Huang Y, Fogel RB, Pillar G, Edwards JK, Kikinis R, Loring $\mathrm{SH}$, White DP. The male predisposition to pharyngeal collapse: importance of airway length. Am J Respir Crit Care Med 2002;166(10):1388-95.

36. Cass AR, Alonso WJ, Islam J, Weller SC. Risk of Obstructive Sleep Apnea in Patients With Type 2 Diabetes Mellitus. Fam Med 2013;45(7):492-500.

37. Chaouat A, Weitzenblum E, Kessler R, Charpentier C, Ehrhart M, Levi-Valensi P, et Zielinski J, Delaunois L, Cornudella R, Moutinho dos Santos J. Sleep-related $\mathrm{O}_{2}$ desaturation and daytime pulmonary haemodynamics in COPD patients with mild hypoxaemia. Eur Respir J 1997;10(8):1730-5.

38. Lewis CA, Fergusson W, Eaton T, Zeng I, Kolbe J. Isolated nocturnal desaturation in COPD: prevalence and impact on quality of life and sleep. Thorax 2009;64(2):133-8.

39. Fletcher EC, Donner CF, Midgren B, zielinski J, Levi-Valensi $P$ Braghiroli A, et Rida Z, Miller CC. Survival in COPD patients with a daytime $\mathrm{PaO}_{2}$ greater than $60 \mathrm{~mm} \mathrm{Hg}$ with and without nocturnal oxyhemoglobin desaturation. Chest 1992;101(3):649-55. 